\title{
QUANTIFICATION AND EVALUATION OF THE KATA PERFORMANCE IN SPORTS KARATE
}

\author{
Nazim Kurtovic
}

Abstract: The text explains the need for studying the peculiarity, the structures of the movements and their evaluation in the kata discipline of sports karate. The author points out that successful communication can not be achieved without quality feedback where the most important element is the relationship between the coach, the athlete and the achieved results.

Keywords: Kata, karate, individualization, mental training, evaluation.

\section{Introduction}

Katas are defined as a combat with imaginary opponents, where the motion structures are aesthetically shaped and choreographically given. Technically, they have a richer and more complex shape than the kumite, and belong to the group of aerobically-anaerobic activities (Doria et all 2009). For the needs of this study, a video analysis of the kata performances of several well-known instructors $^{1}$ and some of the most successful competitors $^{2}$ in the world was made in order to determine the particularity of this discipline. The analysis confirmed that competitors in relation to the instructors, but also in relation to the former champions, often modify the technical elements and the duration of the kata according to the current competitive trends. The primary technical perfection is not the focus of the performance, but the aesthetic shaping and choreography. The athletic performance, in particular, characterizes the expression of strength and speed. On the other hand, athletes have excellent control of the situation in the performance of the kata. The above conclusions served as a pattern in which we directed the research towards finding a method for a more objective evaluation of the kata performance. The karate experts participating in the interview with the author of this text, concluded that the research should be performed (Bompa 2000) with individual treatment of each athlete through cybernetic management with long-term monitoring and permanent flow of information.

\section{Methods and materials}

Since the kata is characterized by a number of diverse technical elements (Doria et all 2009) and their assessment is a complex task, the research was conducted according to the WKF rules, where the efficiency of the kata is assessed on the basis of four main criteria: Conformance, Technical performance, Athletic performance and Technical Difficulty of the kata. We divided the subject of interest into two parts. The first part was analysis of thetechnical elements and the second part was an analysis of the athletic performance and kinesics (Ekman, 1964, 1965; Ekman, Friesen 1969). Also, we determined aesthetic, positional, performance, technical and compositional errors. Every single element was initially set at the level of an ideal performance to a perfect final position, where all deviations from the correct performance were considered as technical errors. Depending on the degree of deviation from the ideal performance, we determined the amount of deductions. For small faults (0.1), for medium (0.3), for large (0.5) and for fatal errors or significant loss of balance (0.7) and falls (1). We applied the same deductions for the same kind of error, regardless of the difficultness of the elements.

Sensei ${ }^{1}$ Hitoshi KASUYA - Jion 1'22"; Goju shiho sho 1'45"; Unsu 1'20"; Sensei 'Mikio YAHARA -Unsu 1'10" Sensei ${ }^{1}$ Yoshiharu OSAKA - Unsu 1'05"; Sensei 1 Atsuko HIGAONNA -Suparimpei 2'05" 2 Yuki Mimura Jion 1'12"; Kanku dai 1'40"; Goju shiho sho 1'35" 2'Luca Valdesi; Jion 1'45"; Kanku dai 2'00"; Goju shiho sho 2'40"; Unsu 2'10"; 2 Michael Milon - Unsu 1'50"; '2 Abe Ryoki -Suparimpei 2'15" ; 'Atsuko Wakai - Suparimpei 3'05" 


\begin{tabular}{|c|c|}
\hline Variable & Check points \\
\hline Conformance (to kata) (C) & $\begin{array}{l}\text { Excessively modified elements that significantly change the meaning and } \\
\text { origin. of the kata }\end{array}$ \\
\hline Stances (St) & $\begin{array}{l}\text { Inadequate width, height, knee angle, hinge and foot rotation, center of } \\
\text { gravity }\end{array}$ \\
\hline Individual techniques (Tec) & $\begin{array}{l}\text { Head position (Head restraint in relation to the vertical axis), shoulder poi } \\
\text { sition (Incorrect angle and tension in the shoulders), position of the hands } \\
\text { and the manipulative part of the hands (Incorrect angle of the forearm in } \\
\text { relation to the shoulder bone, the elbow in correlation of the trunk and the } \\
\text { irregular trajectory, inadequate angle of the palm/fist in relation to the fore- } \\
\text { arm, etc.), the method of lowering the feet on the surface (eg. false landing } \\
\text { with the toe and fingers, the inner part of the foot, etc.) }\end{array}$ \\
\hline $\begin{array}{l}\text { Transition movement/Crossing } \\
\text { from stance to stance }(\mathrm{Tm})\end{array}$ & $\begin{array}{l}\text { Damaged vertical axis and the overall holding of the body, pulling the front } \\
\text { foot toward itself in the event of oi komi or suri komi movement, or pushing } \\
\text { the heel on the back leg when turning backwards or sideways. Position of } \\
\text { the feet in relation to the knees and hips, angle of contact with the surface } \\
\text { (Different segmental compensations due to incorrect rotation in the hips) }\end{array}$ \\
\hline Timing/synchronization $(\mathrm{T})$ & $\begin{array}{l}\text { Performing technique prior to completion of the transition from one to } \\
\text { another position }\end{array}$ \\
\hline Breathing (B) & $\begin{array}{l}\text { Performing parts of the kata in apnea, excessive loud exacerbation of the } \\
\text { throat, mismatched breathing with the performance of the elements }\end{array}$ \\
\hline Focus/Kime (F) & $\begin{array}{l}\text { Levels of prolonged non-contractible time of the technical elements- De- } \\
\text { scribing the instantaneous tensing at the correct moment during a techn. } \\
\text { where certain finality is implied. }\end{array}$ \\
\hline
\end{tabular}

Table 1. Check points of the technical elements in the performance of the kata (Tp), with a coefficient of importance (0.6) according to Nazim Kurtovic

\begin{tabular}{|c|}
\hline Variable \\
\hline Strength $(\mathbf{S t})$ \\
\hline Speed $(\mathbf{S})$ \\
\hline Enbusen $(\mathbf{E})$ \\
\hline Balance $(\mathbf{B})$ \\
\hline Rhythm $(\mathbf{R})$ \\
\hline Kinesics $(\mathbf{K})$ \\
\hline Zanshin $(\mathbf{Z})$ \\
\hline
\end{tabular}

\begin{tabular}{|c|}
\hline \multicolumn{1}{|c|}{ Check points } \\
\hline \multicolumn{1}{|c|}{ General expression of strength } \\
\hline General expression of speed \\
\hline For each kata, the enbusen is fixed and must be accurately monitored \\
\hline Improper holding of the support underneath (center of the body mass) \\
\hline \multicolumn{1}{|c|}{ Proper timing between techniques } \\
\hline $\begin{array}{l}\text { Expression of non-verbal communication - self-confident performance } \\
\text { with a pronounced facial expressions, body posture, gestures, eye move- } \\
\text { ment, and the use of space. Clear understanding of every movement and } \\
\text { proper expression of the idea and fighting spirit, }\end{array}$ \\
\hline \multicolumn{1}{|c|}{ State of full consciousness } \\
\hline
\end{tabular}

Table 2. Check point of the level of athletic performance and kinesics (Apk) with a coefficient of importance $(0.4)$ by Nazim Kurtovic

The next step was to create an evaluation criterion the coefficient of importance 0.4 (tab.2). Each for the main mechanics in the performance. In expert, independently and on previously prepared the evaluation of the specific motor knowledge forms, evaluated each segment separately allocating (technical performance) $\boldsymbol{T} \boldsymbol{p}$, we determined the points from 5 to 10. Similar criteria were used in coefficient of importance 0.6 (tab.1), for the level specific motor tests (Kahrovic et all 2014). During of the specific motor abilities in karate (athletic the evaluation the following standards were applied: performance and kinesics) - Apk, we determined 


\begin{tabular}{|c|c|}
\hline Evaluation rate & Evaluation criteria \\
\hline $\mathbf{1 0}$ points & For a harmonious and synchronized performance of the technical elements without errors \\
\hline $\mathbf{9}$ points & For a very good technique with one of the components slightly distorted - small error \\
\hline $\mathbf{8}$ points & $\begin{array}{r}\text { For very good execution of techniques, occurrence of minor errors, where the basic structure } \\
\text { of the elements is not compromised }\end{array}$ \\
\hline $\mathbf{7}$ points & $\begin{array}{r}\text { For good performance of the technical elements, there is a slightly larger number of errors, but } \\
\text { the basic principles are not significantly disturbed }\end{array}$ \\
\hline $\mathbf{6}$ points & $\begin{array}{r}\text { Where the basic structure of the technique is partially disrupted and uncertain performance is } \\
\text { noticed - presence of more medium and small errors }\end{array}$ \\
\hline $\mathbf{5}$ points & $\begin{array}{r}\text { For poor performance, evidence of larger or fatal defects, the structure of the movement is sub- } \\
\text { stantially impaired, extreme uncertainty is noticed. }\end{array}$ \\
\hline
\end{tabular}

Table 4. Evaluation of the technical performance according to Nazim Kurtovic (2017)

\begin{tabular}{|c|c|}
\hline Evaluation rate & Evaluation criteria \\
\hline $\mathbf{1 0}$ points & $\begin{array}{r}\text { For excellent artistic interpretation of the kata with expressed mechanical energy and non-verk } \\
\text { bal communication. }\end{array}$ \\
\hline $\mathbf{9}$ points & $\begin{array}{r}\text { For high level of interpretation, confident and conclusive, expressed mechanical energy, but } \\
\text { there is still not enough expression of non-verbal communication. }\end{array}$ \\
\hline $\mathbf{8}$ points & $\begin{array}{r}\text { For very good interpretation, but not enough conclusive and slightly unconfident, inappropri- } \\
\text { ate breathing, and not enough expression of non-verbal communication. }\end{array}$ \\
\hline $\mathbf{6}$ points & $\begin{array}{r}\text { For good interpretation, but there no proper timing between the techniques - inappropriate } \\
\text { rhythm, no clear understanding of the movements, inappropriate breathing and no proper } \\
\text { expression of the non-verbal communication }\end{array}$ \\
\hline $\mathbf{5}$ points & $\begin{array}{c}\text { Uncertain athletic performance with inappropriate timing between techniques - inappropriate } \\
\text { rhythm, no clear understanding of the movements, inappropriate breathing and no proper } \\
\text { expression of the non-verbal communication. }\end{array}$ \\
\hline $\begin{array}{c}\text { For poor interpretation, not conclusive and very unconfident, it is missing maximum range } \\
\text { of expression in strength and speed, incorrect enbusen, inappropriate breathing, inappropri- } \\
\text { ate timing between the techniques - inappropriate rhythm and no proper expression of the } \\
\text { non-verbal communication. }\end{array}$ \\
\hline
\end{tabular}

Table 5. Evaluation of athletic performance and the non-verbal communication according to Nazim Kurtovic (2017)

The average results of both segments, collected and multiplied by the corresponding coefficient of importance, formed the final grade for the general performance $(\mathrm{GP})$.

\section{$G p=($ Tp mean $x$ Coefficient $T p)+$ (Apk mean $x$ Coefficient Apk)}

In the next step, it was necessary to examine the level of knowledge and abilities of each individual, and then create the database of the model characteristics of the middle achievements of the group. The diagnosed condition was to be recorded in the personal files. The fourth step required an analysis of the linking and recording of the results of the individual athletes' performance in relation to the average values of the group's model characteristics. In the fifth step, according to the recorded initial condition, a short-term training intervention was planned. According to the results obtained, in the sixth step follows the programming of the individual transformation process. In the seventh step was made an implementation of the training intervention. In the last eighth stage was the complete control testing in order to get a new condition. After the first round were set up new goals, planning, programming and realization of the training intervention until the next testing.

\section{Training intervention}

In the implementation of the training intervention, (Kurtovic, Savova 2016) the advanced model of karate training was used. To correct the technical performance according to the standards of the Shotokan technical organization (WSKF), the problematic key movement patterns should be first identified. Then (Jeffreys 2006), each technique is divided into a series of discrete moving patterns and separated into "target motion mechanics". Since the target mechanics of such movements is based on mechanical principles, the errors were 
clearly perceptible. The exact execution of each individual movement, according to its function and for easier perception of errors, was classified in three phases: an initial phase (Fig. 1); a transitional phase (Fig. 2) and the third actualization phase (Fig. 3). In order to increase the effectiveness of the training, (Knudson, Morrison 1997), we developed a system for identifying the target mechanics for each moving pattern that should be corrected.

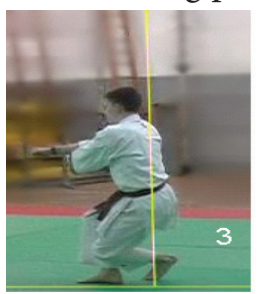

Figure 3

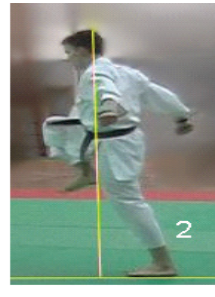

Figure 2

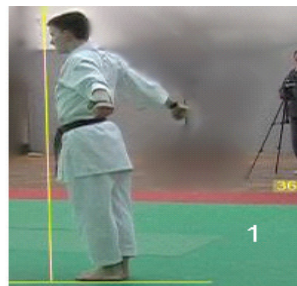

Figure 1
For illustration, when analyzing the individual movement, the "check-point" list included an area of observation - the whole posture, but also each segment separately and the target mechanics for each area separately. According to this example, we made a list for each target moving pattern in each of the analyzed kata. This analysis was a powerful tool that provided a model with which we could compare the performance of the athlete. Once the motion patterns were mastered (according to the expert opinion), the next step was to identify and integrate these discrete motion patterns into sequences that appear in the kata.

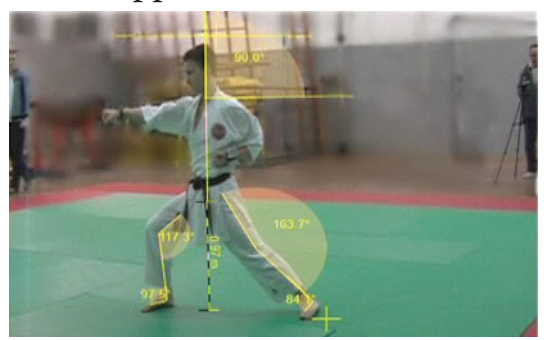

Figure 4

Visualization is the primary mental competence important for the kata, which should be possessed by every competitor. We used it in order for the athletes to be able to think effectively in images and to control the course of images and corrections in a positive direction for the mental intentions to be easily transformed into a motor reaction. In this direction, the model of kumite training (Kurtovic \& Savova 2016) served as a pattern for creating an appropriate model for kata training. Once we introduced the athletes, in the first step, with the techniques and procedures of the training, after the activation phase, through the techniques of progressive relaxation (Jacobson 1938) and KI meditation (K. Tohei 1976), they should have regulated their psychophysiological state. Using the video material with performances of world-class competitors, the athletes imaginary studied various situations and exercises for performing katas in order to improve their technical and athletic performance with kinesics. Otherwise, in such cases, the brain regions known as the "mirror neuron system" show an increased activity when the performer sees the movements he has previously trained. Such findings (Daniel Glaser) suggest that the brain can simulate this movement he learned with a simple observation. In the next steps, the performance should have been projected without error aligned with the practical performance. The next task in the third step was to establish respiratory control and the focus. In the fourth step, for appropriately fulfilling the mechanical energy and in a suitable rhythm, the katas were to be imaginary then practically drawn in the opposite direction (first in parts, then completely), and with the opposite side (mirror effect). The final fifth step followed the practical realization through a situational training, in conditions characteristic for the competition. Verbal support from the environment was involved, by ignoring them, occasionally criticizing or praising their performance. In this context, trainings with Kumite were included on a daily basis due to the realistic sense of the techniques. The demonstrated behavior and realization was a mirror of everything that was trained in the training sessions in the previous steps. After ensuring that in such circumstances "they are ok," we left them alone to use these techniques during the training sessions, and later in the control matches as well. At all of these phases, athletes used mentioned techniques of excitement and relaxation.

\section{Object of the research}

All athletes $(\mathrm{N} 4)$ were male, aged $19.4 \pm 2.7$ years, with $65.5 \pm 6.5 \mathrm{~kg}$ weight and $172.0 \pm 5.2 \mathrm{~cm}$ height. After obtaining consent to participate in the experiments, before each simulation, they were explained in detail the purpose and procedures, as well as the measures for their protection against injuries.

\section{Equipment and stimulators}

For the purpose were used specialized karate dojolaboratory with tatami model bedding: SMAI $2 \mathrm{~cm} ; 5$ cameras Sony PMW-EX1; 4 Sony VCT 1170RM Tripod; Sony portable LCD Projector VPL-X1000 and VPS-120 FH Flat screen, Sony 
HT-CT390 Sound Bar System, DELL Vostro 1720 Laptop PC with Dartfish software installed.

\section{Procedure}

thletes under our control, had a 90-minute training, nine times a week. An audience was provided to capture the competitive atmosphere. 5 video cameras, documented each performance from 4 different angles placed analogously, with the viewpoint of the corner judges. The fifth camera was in the hands of a cameraman focused on the face and torso of the performers, with which the performances and non-verbal communication of the athletes were closely observed (Figure 5). Immediately beside the cameras were located five karate experts, which evaluated and made notes in detail for each performance in previously prepared forms.

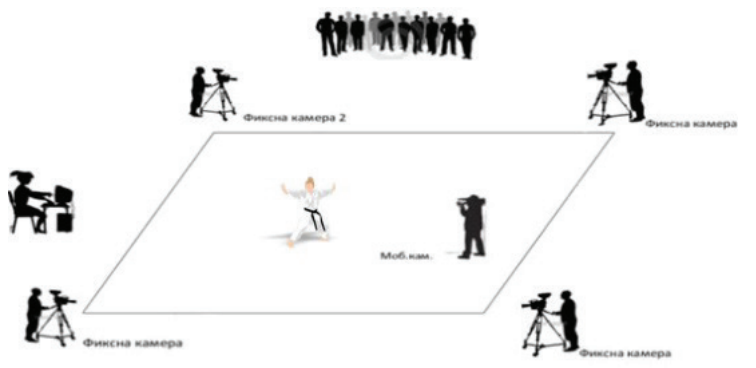

Figure 5. Atmosphere during the measurements

Each athlete had a task to perform five katas per day with a break of 15 to 25 minutes between rounds for breaks and meditative sessions. The recordings were later analyzed with the Dartfish software. In order to avoid subjectivity, the analysis was carried out by an expert team of experts who debated the possible controversial details. The experiment had an initial, control and final measurement with a distance of 6 months between the measurements.

\section{Results and discussion}

In order to prove the hypothesis that continuous individually modeled training influenced the ability for general performance in all tested athletes and from one measurement to another significantly reduced the errors in individual technical and athletic performances including non-verbal communication, we supported our results with comparative statistical analysis made with $M d$ Calc 2013 software where in all comparisons the $p$ value was $\leq 0.05$.

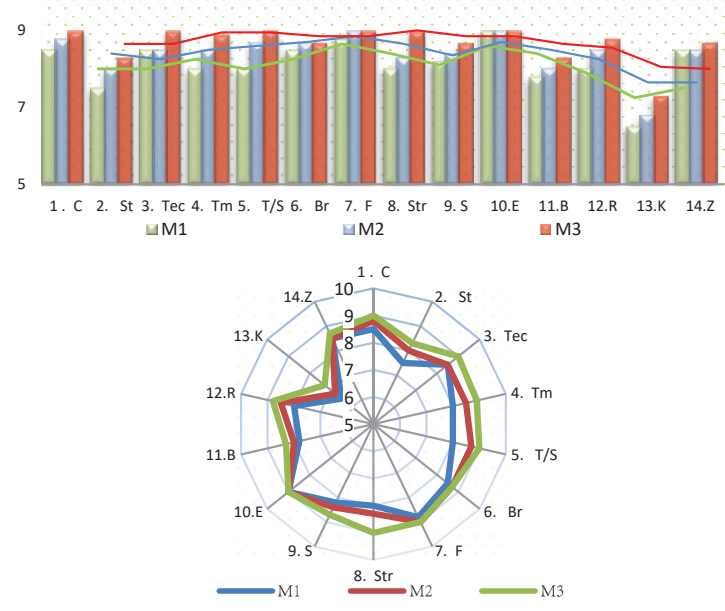

Figure 6 and Figure 7Technically \& Athletic and Kinesics performance Athlete $N$ in first, second and third measurement

As an illustration of Figure 6 and Figure 7, individual results and progress in all variables of the selected athlete during the performance are displayed. The athlete improved its average score from 8.154 to 8.446 on the control measurement after 6 months. At the end of the measurement, the average score improved from 8.446 to 8.729 . When training for the issues in question, the results obtained are illustrations from a relatively short research period, which is another proof that the applied methodology had a positive impact.

1.Conformance (C),2.Stances (St) 3.Techn. El. (Tec) 4.Trans.betw.stances (Tm) 5.Timing/Sinhronisat. (T/S)6.Breathing (Br) 7.Focus/Kime (F) 8.Strength (Str), 9 Speed (S), 10.Enbusen(E),11.Balans (B)12.Rhythm (R),13.Kinesics (K)14.Zanshin (Z)
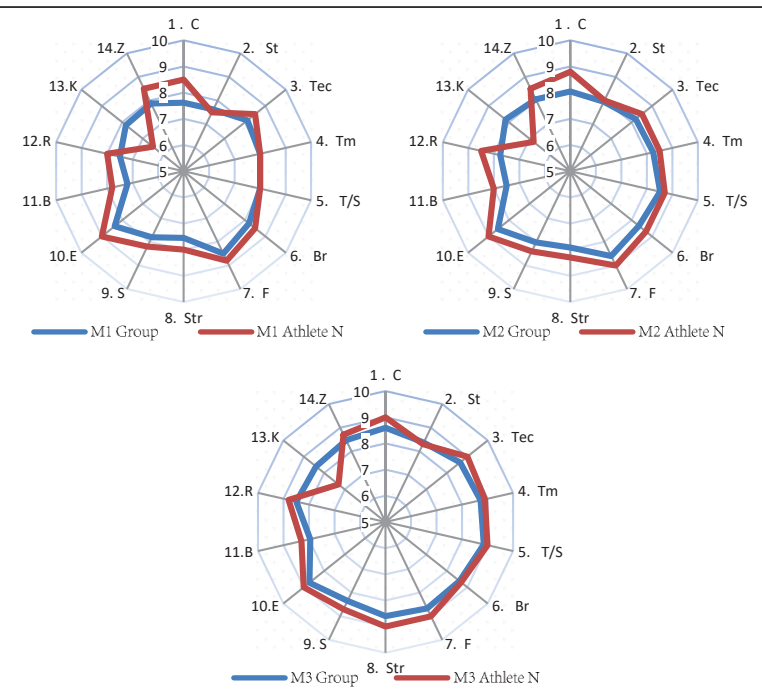

Figure 8, 9 and 10. Difference between average results of group and athlete $\mathrm{N}$ in first, second and third measurement 
On Figure 8, 9 and 10 is presented the progress of the group as a whole, as well as the individual results and deviations of the athlete $(\mathrm{N})$ in relation to the average results of the whole group in the three measurements. Among other things, in the regular athlete polls, there were also questions related to anxiety during kata performances in official competitions, the testimonies confirmed that the essential understanding of what they worked greatly helped them improve the quality of their performance during the training and increase their self-confidence in the competitions. The results of the detailed analysis with the Dartfish software were regularly presented to the athletes and they played a significant role in removing the eventual skepticism in the evaluation process. Namely, through the cinema projection they could realize argumentatively their own weaknesses, thanks to which they increased the cooperativity.

\section{Conclusion}

The presented text is a pilot study focused on the analysis and evaluation of the technical and athletic kata performance. The experience gained in the realization of this research has confirmed that, through the presented methodology, we can significantly influence the improvement of the kata performance in sports karate. Therefore, we believe that this study represents an experience plus and enrichment of the highly deficient literature related to the theory and methodology of sports training in the kata disciplines. It is especially important to note that in the individual treatment, the long-term observation and detailed video analysis enables us to objectively evaluate our work and effectively plan and implement the process of transformation. We believe that this text will be useful and applied by teams in sports karate who aspire to optimize their daily work and open new perspectives for the serious application of the combined method of mental and technical preparation in the training process. In the next period, our goal will be to explore the individual influence of the predictor system on the criteria system of the applied and quantified variables. We hope that this study will be an additional application for the WKF professionals responsible for creating the rules and that they will seriously consider how to objectify the very subjective and unconvincing evaluation of the katas in future. Our recommendation is that in the future, the method of evaluation in kata disciplines should follow the example of already proven indicators in sports and rhythmic gymnastics, synchronized swimming, ice skating, ski jumping and sports jumping in water.

\section{Reference}

Bompa, Tudor (2000) Total Training for Young Champions, Book pp 1-15, Human Kinetics ISBN 0-7360-0212 C.Doria, et All (2009) Energetics of karate (kata and kumite techniques) in top-level athletes Eur J Appl Physiol 107:603-610DOI 10.1007/s00421-009-1154-y

Ekman, P. (1964). Body position, facial expression and verbal behavior during interviews. Journal of Abnormal and Social Psychology, 68, 295-301.

Ekman, P. (1965). Differential communication of affect by head and body cues. Journal of Personality and Social Psychology, 2, 725-735.

Ekman,P.,\& Friesen,W.V.(1969). The repertoire of nonverbal behavior. Semiotica, 1, 49-98.

I.Kahrovic et All; (2014) Differences between karate practitioners of varied competition orientations in specific motor test results Facta Universities Series: Physical Education and Sport Vol.12,N3,2014,pp. 227-239

Jacobson (1938), Progressive Relaxation, University of Chicago Press, Chicago Book

Jeffreys, I (2006) Optimising speed and agility development using target classifications and motor control principles Part One. Professional Strength and Conditioning (3) 11-14

Jeffreys, I (2006) A motor development approach to enhancing agility Part One. Strength and Conditioning Journal.28 (5). 72-76

Jeffreys, I (2006) Optimising speed and agility development using target classificationsand motor control principles Part Two. Professional Strength and Conditioning (4) 12 - 17

Jeffreys, I (2006) A motor development approach to enhancing agility Part Two. Strength and Conditioning Journal. 28(6).10-14.

Koichi Tohei 1976. Book of Ki, Diorama, 1998. - 96 pp.; Zagreb -1998.UDK 133.52 (520) ISBN 953-6573-07-5 980911062) Book

Kurtovic N, Savova N.(2016) Optimization of Performance in Top-Level Athletes during the Kumite in Sport Karate. Journal of Sports Science, David Publishing Company. 616 Corporate Way, Suite 2-4876, Cottage, NY 10989, USA

Knudson D, Morrison C (1997) Quantitative analysis of human movement Champaign, IL: Human Kinetics. Book

Monkey do, monkey Daniel Glaser http://www.pbs.org/ wgbh/nova/sciencenow/3204/01-monkey.html 